\title{
Role of Sphingosine 1-Phosphate (S1P) Receptor 1 in Experimental Autoimmune Encephalomyelitis
}

\section{-I. S1P-S1P1 Axis Induces Migration of Th1 and Th17 Cells}

\author{
Noriyasu Seki ${ }^{1}$, Yasuhiro Maeda ${ }^{1}$, Hirotoshi Kataoka ${ }^{1}, K_{\text {Kunio Sugahara }}{ }^{1}, K^{2}$ ji Chiba $^{1,2^{*}}$ \\ ${ }^{1}$ Pharmacology Research Laboratories I, Research Division, Mitsubishi Tanabe Pharma Corporation, Yokohama, Japan; ${ }^{2}$ Advanced \\ Medical Research Laboratories, Research Division, Mitsubishi Tanabe Pharma Corporation, Yokohama, Japan. \\ Email: *Chiba.Kenji@mk.mt-pharma.co.jp
}

Received October $11^{\text {th }}, 2013$; revised November $2^{\text {nd }}, 2013$; accepted November $12^{\text {th }}, 2013$

Copyright (C) 2013 Noriyasu Seki et al. This is an open access article distributed under the Creative Commons Attribution License, which permits unrestricted use, distribution, and reproduction in any medium, provided the original work is properly cited.

\begin{abstract}
Infiltration of myelin-specific helper T (Th) cells into the central nervous system (CNS) plays a key role in pathogenesis of experimental autoimmune encephalomyelitis (EAE). In this study, we investigated the involvement of sphingosine 1-phosphate (S1P)-S1P receptor 1 (S1P1) axis in lymphocytes for EAE development when C57BL/6 mice were immunized with myelin oliogodendrocyte glycoprotein (MOG). The expression of S1P1 mRNA and S1P responsiveness of lymphocytes in draining lymph nodes (DLN) were down-regulated markedly after MOG immunization until onset of EAE. Accompanying with reacquisition of down-regulated S1P1 transcript and S1P responsiveness in DLN lymphocytes, MOG-immunized mice developed EAE symptoms with significant infiltration of Th1 and Th17 cells into the CNS and a marked elevation of IFN- $\gamma$, T-bet, IL-17, and ROR $\gamma \mathrm{t}$ mRNA expressions. Prophylactic administration of an S1P1 functional antagonist, fingolimod hydrochloride (FTY720, $0.3 \mathrm{mg} / \mathrm{kg}$, orally) significantly inhibited EAE development and almost completely prevented infiltration of Th1 and Th17 cells into the CNS with a marked reduction of IFN- $\gamma$, T-bet, IL-17, and ROR $\gamma$ t mRNA expressions. Similar results were obtained by treatment with an S1P1-selective agonist, SEW2871 or an S1P lyase inhibitor, 2-acetyl-4-tetrahydroxybutylimidazole. Moreover, FTY720-phosphate and SEW2871 inhibited in vitro migration of Th1 and Th17 cells toward S1P but did not affect cytokine production or generation of Th1 or Th17 cells. These results suggest that reacquisition of S1P1 expression in DLN lymphocytes plays a major role in trafficking of myelin antigen-specific Th1/Th17 cells from DLN to the CNS in EAE and that prophylactic effect of FTY720 on EAE is predominantly caused by functional antagonism via lymphocytic S1P1.
\end{abstract}

Keywords: Sphingosine 1-Phosphosphate Receptor 1; Fingolimod Hydrochloride (FTY720); Experimental Autoimmune Encephalomyelitis; Th1 Cells; Th17 Cells

\section{Introduction}

Experimental autoimmune encephalomyelitis (EAE) is a CD4 T cell-mediated inflammatory disease of the central nervous system (CNS) which clinically manifests as ascending paralysis $[1,2]$. It can be induced in susceptible animals by immunization with myelin proteins or peptides or by adoptive transfer of myelin-specific CD4 T cells. EAE shares many clinical and histopathological features with multiple sclerosis (MS) and is a commonly used animal model of this human autoimmune disease $[3,4]$. The generation of effector CD4 T cells is a critical event for the progression of EAE. EAE was believed to

${ }^{*}$ Corresponding author. be a Th1-induced autoimmune disease because of the increased expression of Th1 cytokines in the affected CNS and because injection of myelin specific CD4 Th1 but not Th2 cells into immune-competent mice is sufficient to induce EAE [5-9]. On the other hand, interleukin 17 (IL-17)-producing Th17 cells have been implicated in pathogenesis of EAE [10-12]. It is currently thought that IL-17 up-regulates the expression of pro-inflammatory cytokines/chemokines that mediate inflammation in the CNS to promote EAE $[13,14]$. In contrast, Th2 cells and regulatory $\mathrm{T}$ cells play a protective role in EAE [15-17].

A lipid mediator, sphingosine 1-phosphate (S1P) and its receptor 1 (S1P1) play an essential role in lymphocyte egress from the secondary lymphoid organs (SLO) 
and thymus [18-22]. Fingolimod hydrochloride (FTY720) is a first-in-class, orally active S1P1 receptor functional antagonist [23-28], and has been used as a first oral drug for relapsing MS in more than 70 countries, because of its superior efficacy compared with interferon (IFN)- $\beta$-1a injection in relapsing-remitting MS [29-33]. FTY720 is phosphorylated to FTY720-phosphate (FTY720-P) by sphingosine kinases and FTY720-P down-regulates S1P responsiveness of lymphocytes by internalization and degradation of S1P1 [27,34-36]. Consequently, FTY720$\mathrm{P}$ converted from FTY720 acts as a functional antagonist at lymphocytic S1P1 and inhibits S1P-S1P1 axis-mediated lymphocyte egress from the SLO and thymus [19].

Several reports have been demonstrated that FTY720 shows marked prophylactic and therapeutic effects on EAE in mice and rats [37-41]. As reported previously, oral administration of FTY720 (0.3 to $1 \mathrm{mg} / \mathrm{kg})$ after establishment of EAE showed almost complete preventing effects on relapsing of EAE induced by myelin proteolipid protein (PLP) in SJLJ/ mice [39]. In this EAE model, treatment with FTY720 markedly reduced infiltration of PLP-specific Th17 and Th1 cells into the spinal cord of EAE mice. On the contrary, FTY720 increased the frequency of PLP-specific Th17 and Th1 cells to approximately 3 -fold in inguinal lymph nodes. These findings suggest that FTY720 shows preventing effects on relapsing of EAE by inhibiting egress of myelin antigen-specific Th17 and Th1 cells from draining lymph nodes (DLN).

In this study, we investigated the role of S1P-S1P1 axis in DLN lymphocytes for EAE development when C57BL/6 mice were immunized with myelin oliogodendrocyte glycoprotein (MOG). Our findings suggest that S1P1 expression in DLN lymphocytes was down-regulated immediately after antigen immunization and that the reacquisition of S1P1 expression in DLN lymphocytes triggers the trafficking of Th1 and Th17 cells into the CNS in EAE. We also demonstrate that prophylactic effect of FTY720 on EAE is likely due to sequestration of myelin-specific Th1/Th17 cells into DLN by downregulation of lymphocytic S1P1.

\section{Materials and Methods}

\subsection{Mice}

Inbred strains of female C57BL/6 mice were purchased from Charles River Japan and were used at 7 to 9 weeks of age. All animal experiments were performed under an experimental protocol approved the ethics review committee for animal experimentation of Research Division, Mitsubishi Tanabe Pharma Corporation.

\subsection{Agents and Antibodies}

FTY720 was synthesized according to the method de- scribed previously [23] and was dissolved in distilled water for oral administration. The $(S)$-enantiomer of FTY720-P ( $>99.5 \%$ enantio excess) was synthesized according to the previous method [26] and was dissolved in ethanol for in vitro experiments. An S1P1-selective agonist, SEW2871 and an S1P lyase inhibitor, 2-acetyl4-tetrahydroxybutylimidazole (THI) were synthesized and used according to the respective methods reported previously $[42,43]$. S1P was purchased from Sigma-Aldrich

MOG $_{35-55}$ (MEVGWYRSPFSRVVHLYRNGK) was obtained from Peptide Institute. RPMI 1640 medium was supplemented with $10 \%$ fetal calf serum (FCS) which was pretreated with charcoal, $10 \mathrm{mM}$ HEPES, $50 \mathrm{U} / \mathrm{ml}$ penicillin, $50 \mu \mathrm{g} / \mathrm{ml}$ streptomycin, $0.1 \mathrm{mM}$ non-essential amino acids, $1 \mathrm{mM}$ sodium pyruvate, and $50 \mu \mathrm{M} 2$-mercaptoethanol. Cy-Chrome-conjugated rat anti-mouse CD4 monoclonal antibody (mAb) (GK1.5), fluorescein isothiocyanate (FITC)-conjugated rat anti-mouse IFN- $\gamma$ $\mathrm{mAb}$ (XMG1.2), phycoerythrin (PE)-conjugated rat antimouse IL-17 mAb (TC11-18H10.1), PE-conjugated rat anti-mouse CD3 mAb (RA3-6B2), and Cy-Chrome-conjugated rat anti-mouse $\mathrm{CD} 8 \mathrm{mAb}(53$ - 6.7) were purchased from BD Bioscience. Hamster anti-mouse CD3 $\mathrm{mAb}$ (145-2C11), FITC-conjugated rat anti-mouse CD4 $\mathrm{mAb}$ (RM4-5), hamster anti-mouse CD28 mAb (37.51), and rat anti-mouse CD16/32 mAb (93, FcR block) were purchased from eBiosciences. Rat anti-mouse IFN- $\gamma$ $\mathrm{mAb}$ (RMMG-1) and rat anti-mouse IL-4 mAb (11B11) were obtained from Biosource. IL-2, IL-6, and transforming growth factor (TGF)- $\beta 1$ were purchased from Peprotech. IL-23 was obtained from R\&D Systems.

\subsection{EAE Induction}

For the induction of EAE, C57BL/6 mice received a single immunization of $\mathrm{MOG}_{35-55}$ in Freund's complete adjuvant containing killed Mycobacterium tuberculosis H37Ra subcutaneously on day 0 , followed by intravenous injection with $200 \mathrm{ng}$ of pertussis toxin (List Biological Laboratories) on day 0 and 2 [39]. Individual mice were scored for clinical signs of EAE using the following criteria: 0 , no paralysis; 0.5 , stiff tail; 1 , limp tail; 1.5 , limp tail with inability to right; 2 , paralysis of one limb; 2.5, paralysis of one limb and weakness of one other limb; 3, complete paralysis of both hind limbs; 4 , moribund state; 5 , death.

\subsection{Real Time Polymerase Chain Reaction}

Total RNA was extracted using TRIZOL (Invitrogen) and concentrations of total RNA were measured spectrophotometrically. A two-step quantitative reversetranscriptation-polymerase chain reaction (RT-PCR) was performed to determine various molecules mRNA ex- 
pression using the relative standard curve method, with cellular housekeeping enzyme, GAPDH as the normalization control. Complementary DNA was synthesized with TaqMan Reverse Transcription Reagents (Applied Biosystems) using random hexamers and $0.5 \mu \mathrm{g}$ of total RNA. Real-time PCR was performed with an ABI PRISM 7900 Sequence Detection System (Applied Biosystems). In the real-time PCR, following TaqMan probes (6-carboxy-fluorecein label)/primers were used: CD3 (Mm00599683_m1), IFN- $\gamma$ (Mm00801778_m1), TNF- $\alpha$ (Mm00443258_m1), T-bet (Mm00450960_m1), IL-17 (Mm00439619_m1), TGF- $\beta 1$ (Mm00441724_m1), IL-6 (Mm00446190_m1), and IL-23 (Mm00518984_m1) in the presence of GAPDH TaqMan probe (VIC label)/ primer. To measure the level of mRNA of S1P1 and $\mathrm{ROR} \gamma \mathrm{t}$, real time PCR was performed with an ABI PRISM 7900 sequence detector using SYBR Green PCR master mix (Applied Biosystems). The following primer pairs were used $\left(5^{\prime} \rightarrow 3^{\prime}\right)$ : S1P1 forward, AAA TGC CCC AAC GGA GAC T; S1P1 reverse, CTG ATT TGC TGC GGC TAA ATT C [34], ROR $\gamma$ t forward, CCG CTG AGA GGG CTT CAC; ROR $\gamma$ t reverse, TGC AGG AGT AGG CCA CAT TAC A [44]. The reaction was incubated for $2 \mathrm{~min}$ at $50^{\circ} \mathrm{C}$ denatured for $10 \mathrm{~min}$ at $95^{\circ} \mathrm{C}$ and subjected to 40 step amplification cycles with annealing/extension at $60^{\circ} \mathrm{C}$ for $1 \mathrm{~min}$ followed by denaturation at $95^{\circ} \mathrm{C}$ for $15 \mathrm{~s}$. Data were analyzed using Sequence Detector software (Applied Biosystems). For quantification, standard curves were generated for various molecules using serially diluted cDNA samples from the spinal cord in EAE mice (day 14 after immunization). For every sample, the level of mRNA normalized by calculating the ratio of each target molecule/GAPDH level.

\subsection{Intracellular Cytokines Staining}

Lymphocytes prepared from the inguinal lymph nodes or spinal cords were stimulated with $50 \mathrm{ng} / \mathrm{ml}$ phorbol-12myristate-13-acetate and $500 \mathrm{nM}$ ionomycin in the presence of $2 \mu \mathrm{M}$ monensin for $5 \mathrm{~h}$ in RPMI 1640 medium containing $10 \% \mathrm{FCS}$ at $37^{\circ} \mathrm{C}$ in $5 \% \mathrm{CO}_{2}$. After blocking with rat anti-mouse CD16/32 mAb, the cells were stained with Cy-Chrome-conjugated anti-mouse CD4 mAb and permeabilized with $0.5 \%$ Triton $\mathrm{X}-100$. The intracellular cytokine staining was carried out by using FITC-conjugated anti-mouse IFN- $\gamma \mathrm{mAb}$ and PE-conjugated antimouse IL-17 mAb. Flow cytometry analysis was conducted using FACScan with CellQuest software (Becton Dickinson).

\subsection{Migration Assay}

Migration assays were conducted according to the method described previously [34]. After serum starvation, mouse inguinal lymph node lymphocytes $\left(5 \times 10^{5}\right.$ cells $)$ were added to the upper wells of 5- $\mu$ m pore, polycarbonate 24-well tissue culture inserts (Costar) in $100 \mu \mathrm{l}$, with $600 \mu \mathrm{l}$ of $10 \mathrm{nM} \mathrm{S1P}$ solution or medium in the bottom wells. All migration assays were conducted in RPMI 1640 medium containing $0.5 \%$ fatty acid free bovine serum albumin for $3 \mathrm{~h}$ at $37^{\circ} \mathrm{C}$ in $5 \% \mathrm{CO}_{2}$. The migrated cells recovered from each well were counted using comparison to a known number of beads as an internal standard of Flow-Count fluorosphere (Beckman Coulter), and were stained with appropriate mAbs to identify CD4 T cells, Th1 cells, and Th17 cells. The number of the cells in the starting population and the migrated population was determined by flow cytometry with an EpicsXL (Beckman Coulter), calculated for each phenotype, and the percent migration was determined from these values.

\subsection{Generation of Th1 and Th17 Cells in Vitro}

Mouse spleen cells were purified to $>95 \%$ of CD4 T cell by passing through mouse CD4 subset enrichment columns (R\&D Systems). CD4 T cells $\left(10^{6}\right.$ cells) were stimulated with anti-CD3 mAb $(10 \mu \mathrm{g} / \mathrm{ml})$ and anti-CD28 $\mathrm{mAb}(1 \mu \mathrm{g} / \mathrm{ml})$ in RPMI 1640 medium containing $10 \%$ FCS for $48 \mathrm{~h}$ under Th1 condition: anti-IL-4 mAb (20 $\mu \mathrm{g} / \mathrm{mL})$; or Th17 condition: IL-6 (20 ng/ml), TGF- $\beta 1$ (10 $\mathrm{ng} / \mathrm{ml})$, anti-IFN- $\gamma \mathrm{mAb}(10 \mu \mathrm{g} / \mathrm{ml})$, and anti-IL-4 mAb $(20 \mu \mathrm{g} / \mathrm{ml})[11,45]$. Then the cells under Th1 or Th17 condition were added IL-2 $(10 \mathrm{ng} / \mathrm{ml})$ or IL-23 $(5 \mathrm{ng} / \mathrm{ml})$, respectively and cultured for additional $96 \mathrm{~h}$. Proportions of Th1/Th17 cells were analyzed by intracellular cytokine staining according to the method as described above. The recovered cells $\left(2.5 \times 10^{4}\right.$ cells $)$ were re-stimulated with anti-CD3mAb plus anti-CD28 mAb for $24 \mathrm{~h}$ and amounts of IFN- $\gamma$ and IL-17 in the culture supernatants were determined by ELISA.

\subsection{Statistical Analyses}

Results were express as the mean \pm standard error mean (SEM). Statistical differences of EAE clinical scores were analyzed by Mann-Whitney $U$ test. In other experiments, statistical differences were calculated by Student's $t$-test. Differences between groups were considered significant when $\mathrm{p}<0.05\left(^{*}: \mathrm{p}<0.05,{ }^{* *}: \mathrm{p}<0.01\right)$.

\section{Results}

\subsection{Reacquisition of S1P1 Expression in DLN Lymphocytes Triggers Infiltration of Th1/Th17 Cells into the CNS}

When C57BL/6 mice were immunized with $\mathrm{MOG}_{35-55}$ peptide on day 0 , one mouse developed EAE on day 11 and more than $80 \%$ of mice showed EAE associated symptoms on day 14 . To investigate the involvement of 
S1P-S1P1 axis in EAE development, we analyzed S1P1 mRNA expression in the inguinal DLN by real time RT-PCR and S1P responsiveness of DLN lymphocytes by migration assay toward $10 \mathrm{nM} \mathrm{S1P.} \mathrm{As} \mathrm{shown} \mathrm{in}$ Figure 1(A), mean clinical scores were significantly elevated on day 14 to 28 . The S1P1 mRNA expression in DLN down-regulated markedly on day 3, was maintained low until onset of EAE (day 9), and thereafter recovered gradually along with EAE development. Similarly, S1P responsiveness of DLN lymphocytes decreased markedly on day 3, was kept low until day 11, and thereafter returned to the level comparable with that before immunization. The mRNA expressions of IFN- $\gamma$ and IL-17 in DLN increased significantly on day 3 to 6 and then decreased to the level before immunization (Figure 1(B)). On the other hand, the mRNA expressions of IFN- $\gamma$ and IL-17 in the spinal cord elevated siginificantly on day 14 to 28 whereas no detectable level of IFN- $\gamma / \mathrm{IL}-17$ mRNA was found before EAE onset (day 6) (Figure 1(C)).

Next, we analyzed infiltration of Th1 and Th17 cells into the spinal cord of EAE mice. As shown in Figure 2(A), proportions of Th1 cells and Th17 cells in DLN began to increase on day 3, peaked on day 6 to 9 , and decreased gradually along with EAE development. On the other hand, significant numbers of Th1 cells $(22.4 \%$ to $52.3 \%$ of CD4 $\mathrm{T}$ cells) and Th17 cells (4.4\% to $5.1 \%$ of CD4 T cells) were infiltrated into the spinal cord of EAE mice on day 14 to 28 (Figure 2(B)). We also confirmed no infiltration of Th1/Th17 cells in the spinal cord before the onset of EAE (data not shown). These results

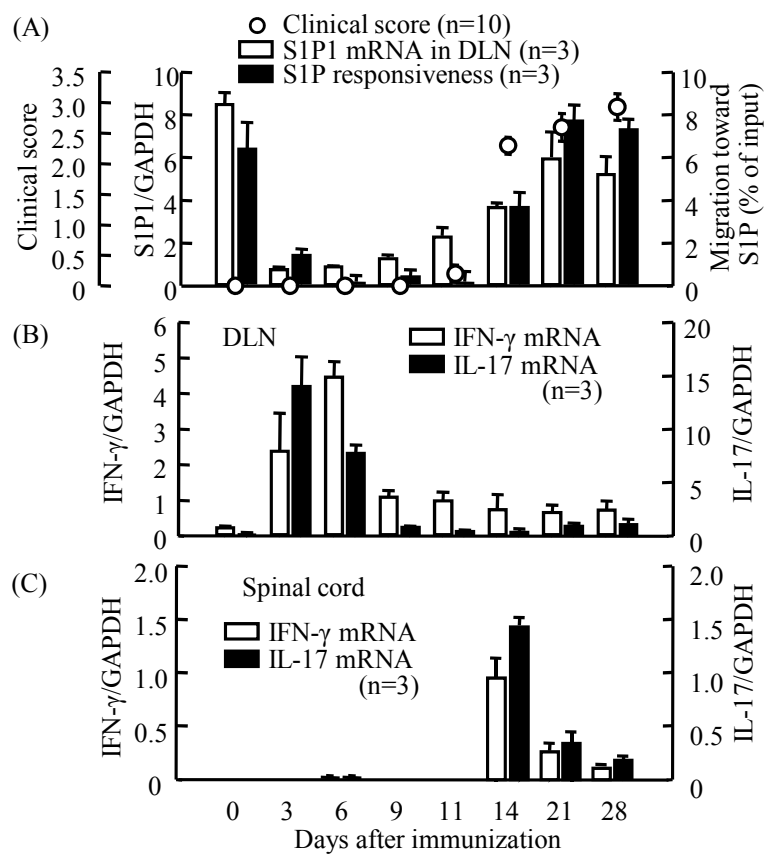

Figure 1. S1P1 transcript and S1P responsiveness in DLN, and IFN- $\gamma /$ IL-17 mRNA expression in the DLN and spinal cord of EAE mice.
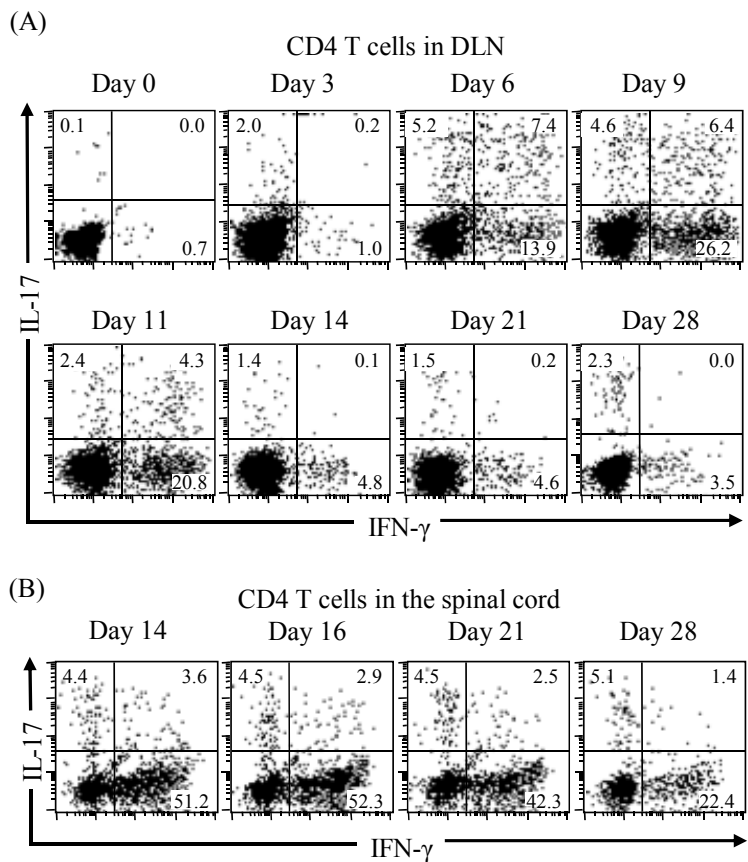

Figure 2. Frequency of Th1 and Th17 cells in the DLN and spinal cord of EAE mice.

suggest that reacquisition of S1P1 expression in DLN lymphocytes triggers infiltration of Th1/Th17 cells into the CNS and EAE development.

\subsection{FTY720 Inhibits EAE by Reducing Infiltration of Th1/Th17 Cells into the CNS}

To clarify the involvement of S1P1 on trafficking of Th1/Th17 cells from DLN to the CNS, we administered FTY720 $(0.3 \mathrm{mg} / \mathrm{kg}$, orally once a day) from day 0 to 16 to $\mathrm{MOG}_{35-55}$-immunized mice. Consistent with previous studies, the prophylactic administration of FTY720 resulted in a marked delay in the onset of EAE with a significant decrease of mean clinical scores (Figure 3(A)). The mRNA expressions of CD3, IFN- $\gamma$, TNF- $\alpha$, T-bet, IL-17, and ROR $\gamma \mathrm{t}$ in the spinal cords were significantly reduced to less than $10 \%$ of vehicle-treated EAE control on day 16 (Figure 3(B)). We also analyzed the infiltration of Th1 and Th17 cells into the spinal cords by intracellular cytokine staining on day 16. The number of lymphocytes prepared from the spinal cords was extremely decreased to less than $1 \%$ of control by treatment with FTY720 (lymphocytes in the spinal cords: EAE control, $9.4 \times 10^{5}$ cells/5mice; FTY720, $0.05 \times 10^{5}$ cells/5mice). Flow cytometry analyses revealed that FTY720 markedly decreased the numbers of Th1/Th17 cells in the spinal cord of EAE mice (Figure 3(C)).

There were no clear change in mRNA levels of CD3, IFN- $\gamma$, TNF- $\alpha$, and T-bet whereas those of IL-17 and ROR $\gamma \mathrm{t}$ were increased to approximately 1.5 -fold in DLN 
(A)
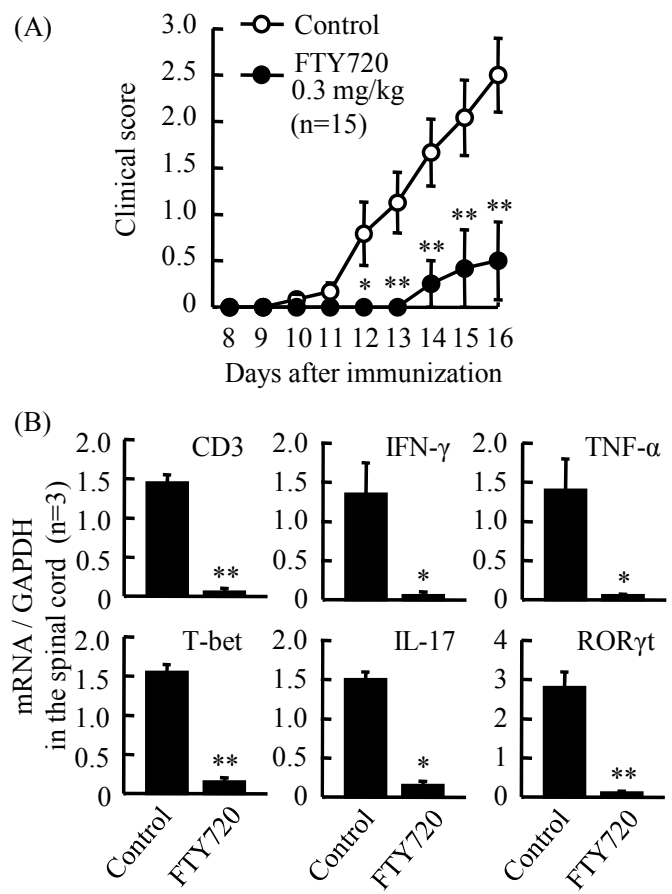

(C)
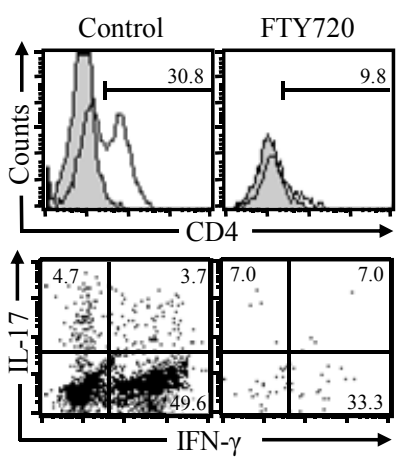

CD4 $\mathrm{T}$ cells in the spinal cord

Figure 3. Prophylactic administration of FTY720 (0.3 $\mathrm{mg} / \mathrm{kg}$ p.o.) inhibits EAE and decreases infiltration of Th1 and Th17 cells into the spinal cord of EAE mice.

of EAE mice given FTY720 (Figure 4(A)). In addition, no change was seen in mRNA level of IL-6, TGF- $\beta 1$, or IL-23 (data not shown). Flow cytomery analyses demonstrated that the proportions of Th1 and Th17 cells in DLN are increased to 2- to 4-fold by FTY720 treatment (Figure 4(B)). These findings suggest that prophylactic FTY720 inhibits EAE development by sequestrating Th1/Th17 cells into the DLN and reducing infiltration of these Th cells to the CNS.

\subsection{S1P-S1P1 Axis Regulates Trafficking of Th1/Th17 Cells from DLN to the CNS in EAE}

An S1P1-selective agonist, SEW2871 and an S1P lyase inhibitor, THI have shown to reduce circulating lymphocytes in the blood by inhibiting S1P1-dependent lym-
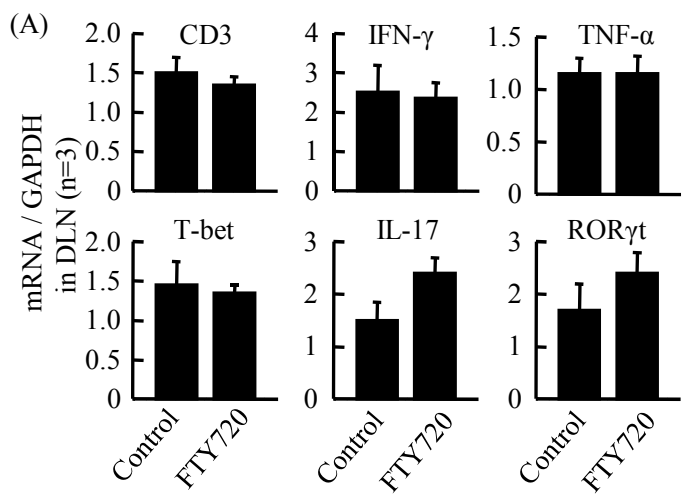

(B)
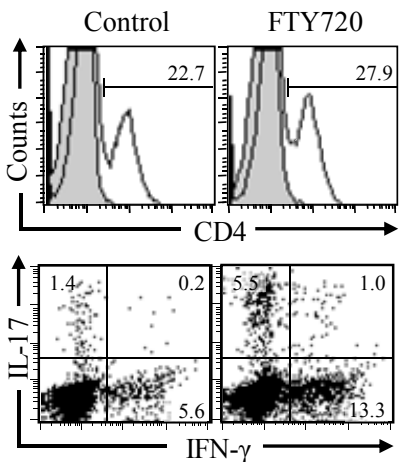

CD4 T cells in DLN

Figure 4. Prophylactic administration of FTY720 (0.3 $\mathrm{mg} / \mathrm{kg}$ p.o.) increases proportions of Th1 and Th17 ells in DLN of EAE mice.

phocyte egress from the SLO [24,42,46,47]. Prophylactic administration of SEW2871(30 mg/kg, orally twice a day) or THI $(50 \mathrm{mg} / \mathrm{kg}$, orally twice a day) significantly inhibited development of EAE (Figure 5(A)) with a significant reduction of mRNA expressions of CD3, IFN- $\gamma$, TNF- $\alpha$, T-bet, IL-17, and ROR $\gamma$ t (Figure 5(B)). Moreover, SEW2871 and THI markedly decreased the number of CD4 T cells and the proportions of Th1 and Th17 cells in the spinal cord of EAE mice (Figure 5(C)).

\subsection{S1P-S1P1 Axis Induces Migration of Th1 and Th17 Cells}

It has been well documented that S1P-S1P1 axis plays an essential role in lymphocyte egress from the SLO. Indeed, $\mathrm{S} 1 \mathrm{P}$ at 10 to $100 \mathrm{nM}$ induces migration of murine naïve CD4 T cells in vitro; however it remains unclear whether S1P can induce migration of Th1 or Th17 cells.

In this study, we found that S1P (10 nM) significantly induces in vitro migration of both Th1 and Th17 cells from DLN lymphocytes of EAE-established mice (Figure 6(A)). Migration of Th1 cells or Th17 cells toward S1P was almost completely inhibited by pretreatment with FTY720-P at $1 \mathrm{nM}$ or higher (Figure 6(A)). Similar results were obtained by pretreatment with $300 \mathrm{nM}$ SEW 2871 (data not shown). On the other hand, FTY720-P 

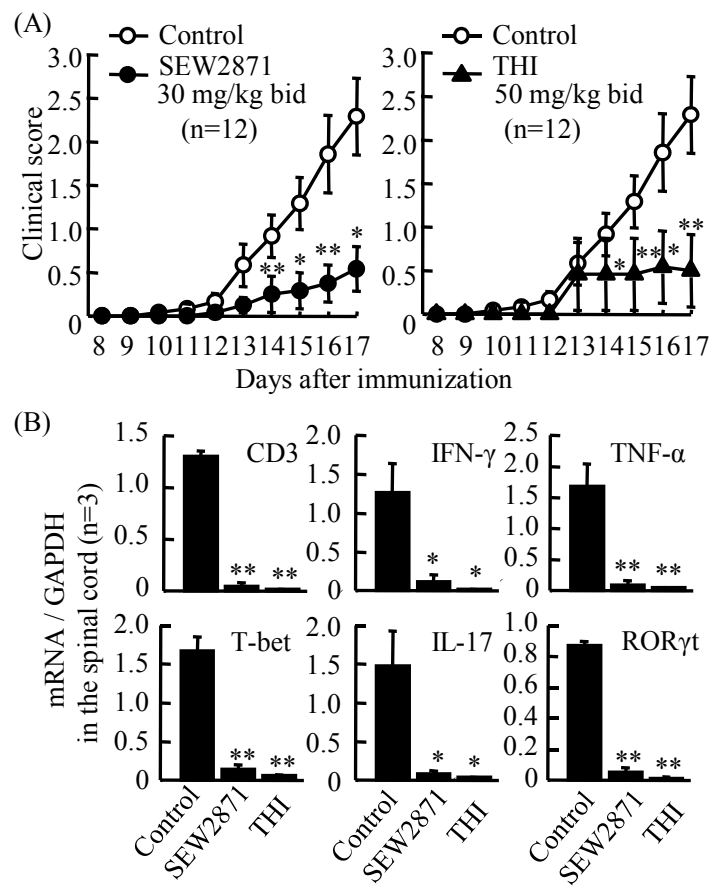

(C)

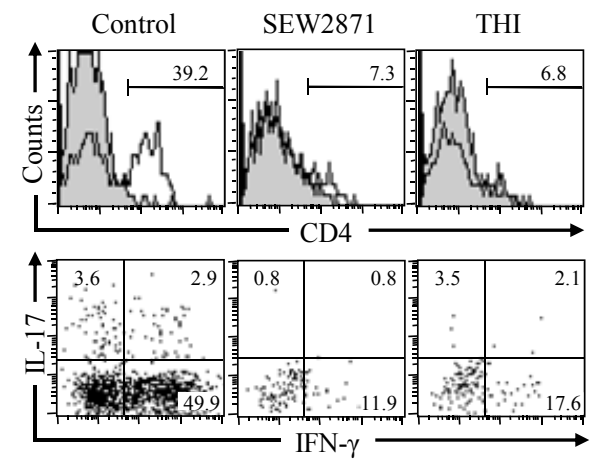

CD4 T cells in the spinal cord

Figure 5. SEW2871 (30 mg/kg p.o. bid) and THI (50 mg/kg p.o. bid) inhibit EAE development and decrease infiltration of Th1 and Th17 cells into the spinal cord of EAE mice.

up to $100 \mathrm{nM}$ did not affect either IFN- $\gamma$ production by Th1 cells or IL-17 production by Th17 cells (Figure 6(B)). Furthermore, FTY720-P showed no effect on generation of either Th1 or Th17 cells in vitro (Figure 6(C)).

\section{Discussion}

EAE is a CD4 T cell-dependent animal model for human MS and development of EAE is likely due to infiltration of encephalitogenic, myelin antigen-specific Th1 cells and/or Th17 cells into the CNS $[3,4,6]$. Since the pathogenic Th1/Th17 cells are originally generated from naïve CD4 T cells after myelin antigen presentation in the DLN [10-12,48-50], trafficking of these Th1/Th17 cells from DLN to CNS is thought to play a key role in EAE development. On the other hand, it is strongly suggested that S1P-S1P1 axis plays an important role in lymphocyte
(A)

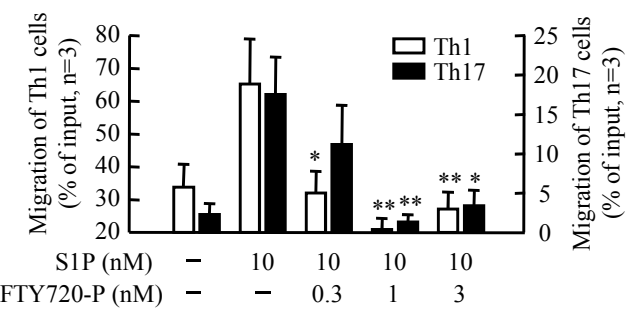

(B)

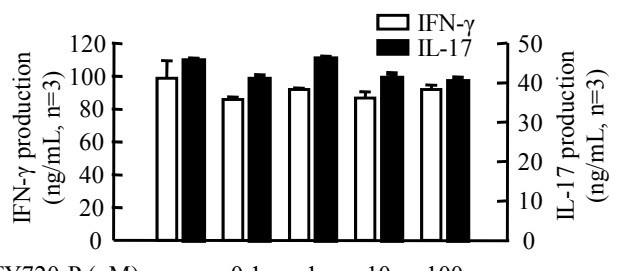

$\begin{array}{llllll}\text { FTY720-P (nM) } & - & 0.1 & 1 & 10 & 100\end{array}$
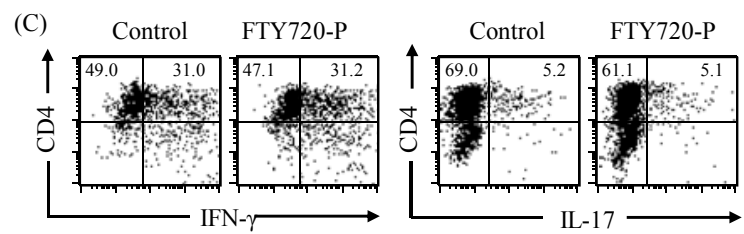

Figure 6. FTY720-P inhibits migration of Th1 and Th17 cells toward S1P but not cytokine production or generation of Th1/Th17 cells.

trafficking between DLN and inflammatory cites because lymphocyte egress from the SLO depends on lymphocytic S1P1 [19]. However it remains unclear relation between S1P-S1P1 axis in DLN lymphocytes including pathogenic Th1/Th17 cells and EAE development.

In the present study, we demonstrated that level of S1P1 mRNA expression in DLN was markedly downregulated after immunization with MOG antigen and was maintained low for several days until EAE development. Similarly, S1P responsiveness of DLN lymphocytes strikingly reduced after antigen exposure and was kept low until the onset of EAE. Our flow cytometry data revealed that the numbers of Th1 cells and Th17 cells increased in DLN before EAE development, suggesting generation of Th1/Th17 cells by antigen stimulation. On the contrary, the number of Th1/Th17 cells decreased in DLN accompanying with the recovery from down-regulated S1P1 transcript and reacquisition of S1P responsiveness in DLN lymphocytes. In parallel, significant numbers of infiltrated Th1/Th17 cells were found in the CNS and most of MOG-immunized mice showed EAE associated symptoms. Namely, our results imply that encephalitogenic Th1/Th17 cells begin to infiltrate into the CNS when down-regulated lymphocytic S1P1 expression is recovered to a homeostatic level in DLN.

During immune response, antigen-specific $\mathrm{T}$ cells are transiently retained within DLN, undergoing activation, and clonal expansion and then exiting as effector cells. This retention mechanism is believed to involve transient 
loss of S1P responsiveness by down-regulation of S1P1 receptor on activated T cells. Matloubian et al. have been reported using OVA-specific DO11.10 TCR transgenic T cells that at one day after antigen exposure, the activated antigen-specific $\mathrm{T}$ cells in DLN had lost their responsiveness to S1P and they had down-regulated S1P1 expression in mRNA level markedly [19]. On the contrary, 3 days after antigen immunization, antigen-specific $\mathrm{T}$ cells appeared in circulation, and lymphocytes in DLN restored S1P responsiveness and increased S1P1 mRNA expression. Therefore, antigen-induced down-regulation of S1P1 transcript and S1P responsiveness is associated with the initial retention of antigen-specific activated $\mathrm{T}$ cells in DLN, and reacquisition of S1P responsiveness is associated with their exit. However, there is no report on lymphocyte retention into DLN by down-regulation of S1P1 transcript after antigen exposure in mouse EAE induced by MOG.

Our findings in MOG-induced mouse EAE clearly demonstrated that S1P1 mRNA expression and S1P responsiveness in DLN were markedly down-regulated after MOG immunization until the onset of EAE whereas the reacquisition of S1P1 mRNA expression and S1P responsiveness in DLN was observed in parallel with the development of EAE. On the other hand, the mRNA expressions of both IFN- $\gamma$ and IL-17 and the frequency of Th1 and Th17 cells in DLN were increased markedly after MOG antigen exposure, suggesting retention of antigen-activated CD4 $\mathrm{T}$ cells in DLN for their maturation to Th1 and Th17 cells. Indeed, CD4 T cells in DLN on day 3 to 9 after MOG antigen immunization showed no detectable migratory response toward S1P.

Prophylactic administration of FTY720, SEW2871, or THI inhibited the development of EAE and decreased the infiltration of Th1 and Th17 cells into the CNS markedly. As reported previously, FTY720-P (0.1 nM or higher) and SEW2871 (300 nM or higher) can induce downregulation of S1P1 in S1P1 stably-expressing Chinese hamster ovary cells and CD4 T cells [34]. On the other hand, THI inhibits S1P lyase activity in vivo and generated high S1P condition down-regulates S1P1 expression [42]. From these results, it is presumed that prophylactic administration of these compounds in vivo induces downregulation of S1P1 and loss of S1P responsiveness in lymphocytes and inhibits egress of pathogenic Th1 and Th17 cells from DLN in EAE mice.

Although it has been reported that naïve murine CD4 $\mathrm{T}$ cells migrate 10 to $100 \mathrm{nM} \mathrm{S1P}$ [19], it remained unclear whether Th1 or Th17 cells can migrate toward S1P. Our results clearly demonstrated that S1P $(10 \mathrm{nM})$ can induce migratory response of both Th1 and Th17 cells prepared from EAE mice. Furthermore, pretreatment with FTY720-P or SEW2871 almost completely inhibited the migration of Th1 and Th17 cells toward S1P.
These results suggest that S1P at physiological concentration induces migration of encephalitogenic Th1 and Th17 cells via S1P1 and that FTY720-P leads to loss of S1P responsiveness of these Th cells by internalization and subsequent degradation of S1P1.

Liao et al. have been reported that like IL-23, S1P at $1000 \mathrm{nM}$ can enhance generation of Th17 cells when $\mathrm{CD} 4 \mathrm{~T}$ cells were stimulated with anti-CD3 mAb plus anti-CD28 mAb and a mixture of TGF- $\beta 1$, IL-1, and IL-6 [51]. Since FTY720-P at $100 \mathrm{nM}$ inhibits IL-17 production from CD4 T cells by stimulation with $1000 \mathrm{nM} \mathrm{S1P}$, it is proposed that immunosuppression by FTY720 may be attributable partly to inhibition of Th17-mediated inflammation. On other hand, our results indicate that FTY720-P up to $100 \mathrm{nM}$ showed no effect on generation or cytokine production of Th1 and Th17 cells without adding exogenous S1P. Furthermore, when THI is administered to mice, S1P concentrations increased to approximately 10 to 100 -fold in the blood, lymph, and SLO $[42,46]$; however no enhancement of frequency of Th17 cells in DLN lymphocytes was seen in THI-treated EAE mice. Because S1P concentrations are kept low in the SLO [42,46], it is likely that low S1P condition in DLN does not affect the generation of Th17 cells.

In conclusion, our results in this study imply that S1P-S1P1 axis induces migration of Th1 and Th17 cells and plays a regulatory role in the trafficking of pathogenic Th1 and Th17 cells from DLN to the CNS in EAE development.

\section{Acknowledgements}

We thank Dr. Kunitomo Adachi in Medicinal Chemistry Laboratories I, Mitsubishi Tanabe Parma Corporation for synthesizing (S)-enantiomer of FTY720-P, SEW2871 and THI.

\section{REFERENCES}

[1] G. D. A. Hafler, "Multiple Sclerosis," Journal of Clinical Investigation, Vol. 113, No. 6, 2004, pp. 788-794.

[2] V. K. Kuchroo, A. C. Anderson, H. Waldner, M. Munder, E. Bettelli and L. B. Nicholson, "T Cell Response in Experimental Autoimmune Encephalomyelitis (EAE): Role of Self and Cross-Reactive Antigens in Shaping, Tuning, and Regulating the Autopathogenic T Cell Repertoire," Annual Review of Immunology, Vol. 20, 2002, pp. 101123.

http://dx.doi.org/10.1146/annurev.immunol.20.081701.14 $\underline{1316}$

[3] R. Martin and H. F. McFarland, "Immunological Aspects of Experimental Allergic Encephalomyelitis and Multiple Sclerosis," Critical Reviews in Clinical Laboratory Sciences, Vol. 32, No. 2, 1995, pp. 121-182. http://dx.doi.org/10.3109/10408369509084683

[4] L. Steinman, "Assessment of Animal Models for MS and 
Demyelinating Disease in the Design of Rational Therapy," Neuron, Vol. 24, No. 3, 1999, pp. 511-514. http://dx.doi.org/10.1016/S0896-6273(00)81107-1

[5] S. D. Miller and W. J. Karpus, "The Immunopathogenesis and Regulation of T-Cell-Mediated Demyelinating Diseases," Immunology Today, Vol. 15, No. 8, 1994, pp. 356-361. http://dx.doi.org/10.1016/0167-5699(94)90173-2

[6] V. K. Kuchroo, C. A. Martin, J. M. Greer, S. T. Ju, R. A. Sobel and M. E. Dorf, "Cytokines and Adhesion Molecules Contribute to the Ability of Myelin Proteolipid Protein-Specific T Cell Clones to Mediate Experimental Allergic Encephalomyelitis," Journal of Immunology, Vol. 151, No. 8, 1993, pp. 4371-4382.

[7] M. K. Kennedy, D. S. Torrance, K. S. Picha and K. M. Mohler, "Analysis of Cytokine mRNA Expression in the Central Nervous System of Mice with Experimental Autoimmune Encephalomyelitis Reveals that IL-10 mRNA Expression Correlates with Recovery," Journal of Immunology, Vol. 149, No. 7, 1992, pp. 2496-2505.

[8] L. Steinman, R. Martin, C. Bernard, P. Conlon and J. R. Oksenberg, "Multiple Sclerosis: Deeper Understanding of Its Pathogenesis Reveals New Targets for Therapy," Annual Review of Neuroscience, Vol. 25, 2002, pp. 491-505. http://dx.doi.org/10.1146/annurev.neuro.25.112701.142913

[9] J. J. Lafaille, F. V. Keere, A. L. Hsu, J. L. Baron, W. Haas, C. S. Raine and S. Tonegawa, "Myelin Basic Protein-Specific T Helper 2 (Th2) Cells Cause Experimental Autoimmune Encephalomyelitis in Immunodeficient Hosts Rather than Protect Them from the Disease," Journal of Experimental Medicine, Vol. 186, No. 2, 1997, pp. 307312. http://dx.doi.org/10.1084/jem.186.2.307

[10] C. L. Langrish, Y. Chen, W. M. Blumenschein, J. Mattson, B. Basham, J. D. Sedgwick, T. McClanahan, R. A. Kastelein and D. J. Cua, "IL-23 Drives a Pathogenic T Cell Population That Induces Autoimmune Inflammation," Journal of Experimental Medicine, Vol. 201, No. 2, 2005, pp. 233-240. http://dx.doi.org/10.1084/jem.20041257

[11] E. Bettelli, Y. Carrier, W. Gao, T. Korn, T. B. Strom, M. Oukka, H. L. Weiner and V. K. Kuchroo, "Reciprocal Developmental Pathways for the Generation of Pathogenic Effector TH17 and Regulatory T Cells," Nature, Vol. 441, No. 7090, 2006, pp. 235-238. http://dx.doi.org/10.1038/nature04753

[12] Y. Komiyama, S. Nakae, T. Matsuki, A. Nambu, H. Ishigame, S. Kakuta, K. Sudo and Y. Iwakura, "IL-17 Plays an Important Role in the Development of Experimental Autoimmune Encephalomyelitis," Journal of Immunology, Vol. 177, No. 1, 2006, pp. 566-573.

[13] H. Park, Z. Li, X. O. Yang, S. H. Chang, R. Nurieva, Y. H. Wang, Y. Wang, L. Hood, Z. Zhu, Q. Tian and C. Dong, "A Distinct Lineage of CD4 T Cells Regulates Tissue Inflammation by Producing Interleukin 17," Nature Immunology, Vol. 6, No. 11, 2005, pp. 1133-1141. http://dx.doi.org/10.1038/ni1261

[14] P. Ye, P. B. Garvey, P. Zhang, S. Nelson, G. Bagby, W. R. Summer, P. Schwarzenberger, J. E. Shellito and J. K. Kolls, "Interleukin-17 and Lung Host Defense against Klebsiella Pneumoniae Infection," American Journal of
Respiratory Cell and Molecular Biology, Vol. 25, No. 3, 2001, pp. 335-340.

http://dx.doi.org/10.1165/ajrcmb.25.3.4424

[15] T. Chitnis, N. Najafian, C. Benou, A. D. Salama, M. J. Grusby, M. H. Sayegh and S. J. Khoury, "Effect of Targeted Disruption of STAT4 and STAT6 on the Induction of Experimental Autoimmune Encephalomyelitis," Journal of Clinical Investigation, Vol. 108, No. 5, 2001, pp. 739-747.

[16] M. Falcone, A. J. Rajan, B. R. Bloom and C. F. Brosnan, "A Critical Role for IL-4 in Regulating Disease Severity in Experimental Allergic Encephalomyelitis as Demonstrated in IL-4-deficient C57BL/6 Mice and BALB/c Mice," Journal of Immunology, Vol. 160, No. 10, 1998, pp. 4822-4830.

[17] A. P. Kohm, P. A. Carpentier, H. A. Anger and S. D. Miller, "Cutting Edge: CD4+CD25+ Regulatory T Cells Suppress Antigen-Specific Autoreactive Immune Responses and Central Nervous System Inflammation during Active Experimental Autoimmune Encephalomyelitis," Journal of Immunology, Vol. 169, No. 9, 2002, pp. 4712-4716.

[18] S. Mandala, R. Hajdu, J. Bergstrom, E. Quackenbush, J. Xie, J. Milligan, R. Thornton, G. J. Shei, D. Card, C. Keohane, M. Rosenbach, J. Hale, C. L. Lynch, K. Rupprecht, W. Parsons and H. Rosen, "Alteration of Lymphocyte Trafficking by Sphingosine-1-Phosphate Receptor Agonists," Science, Vol. 296, No. 5566, 2002, pp. 346-349. http://dx.doi.org/10.1126/science.1070238

[19] M. Matloubian, C. G. Lo, G. Cinamon, M. J. Lesneski, Y. $\mathrm{Xu}$, V. Brinkmann, M. L. Allende, R. L. Proia and J. G. Cyster, "Lymphocyte Egress from Thymus and Peripheral Lymphoid Organs Is Dependent on S1P Receptor 1," Nature, Vol. 427, No. 6972, 2004, pp. 355-360. http://dx.doi.org/10.1038/nature02284

[20] J. G. Cyster, "Chemokines, Sphingosine-1-Phosphate, and Cell Migration in Secondary Lymphoid Organs," Annual Review of Immunology, Vol. 23, 2005, pp. 127159.

http://dx.doi.org/10.1146/annurev.immunol.23.021704.11 $\underline{5628}$

[21] C. G. Lo, Y. Xu, R. L. Proia and J. G. Cyster, "Cyclical Modulation of Sphingosine-1-Phosphate Receptor 1 Surface Expression during Lymphocyte Recirculation and Relationship to Lymphoid Organ Transit," Journal of Experimental Medicine, Vol. 201, No. 2, 2005, pp. 291301. http://dx.doi.org/10.1084/jem.20041509

[22] T. H. Pham, T. Okada, M. Matloubian, C. G. Lo and J. G. Cyster, "S1P1 Receptor Signaling Overrides Retention Mediated by G Alpha i-Coupled Receptors to Promote T Cell Egress," Immunity, Vol. 28, No. 1, 2008, pp. 122133. http://dx.doi.org/10.1016/j.immuni.2007.11.017

[23] K. Adachi, T. Kohara, N. Nakao, M. Arita, K. Chiba, T. Mishina, S. Sasaki and T. Fujita, "Design, Synthesis, and Structure Activity Relationships of 2-Substitued-2-Amino1,3-Propanediols: Discovery of a Novel Immunosuppressant, FTY720," Bioorganic \& Medicinal Chemistry Letters, Vol. 5, 1995, pp. 853-856. http://dx.doi.org/10.1016/0960-894X(95)00127-F

[24] K. Chiba, "FTY720, a New Class of Immunomodulator, 
Inhibits Lymphocyte Egress from Secondary Lymphoid Tissues and Thymus by Agonistic Activity at Sphingosine 1-Phosphate Receptors," Pharmacology and Therapeutics, Vol. 108, No. 3, 2005, pp. 308-319.

http://dx.doi.org/10.1016/j.pharmthera.2005.05.002

[25] V. Brinkmann, M. D. Davis, C. E. Heise, R. Albert, S. Cottens, R. Hof, C. Bruns, E. Prieschl, T. Baumruker, P. Hiestand, C. A. Foster, M. Zollinger and K. R. Lynch, "The Immune Modulator FTY720 Targets Sphingosine 1-Phosphate Receptors," Journal of Biological Chemistry, Vol. 277, No. 24, 2002, pp. 21453-21457. http://dx.doi.org/10.1074/jbc.C200176200

[26] M. Kiuchi, K. Adachi, A. Tomatsu, M. Chino, S. Takeda, Y. Tanaka, Y. Maeda, N. Sato, N. Mitsutomi, K. Sugahara and K. Chiba, "Asymmetric Synthesis and Biological Evaluation of the Enantiomeric Isomers of the Immunosuppressive FTY720-Phosphate," Bioorganic and Medicinal Chemistry, Vol. 13, No. 2, 2005, pp. 425-432. http://dx.doi.org/10.1016/j.bmc.2004.10.008

[27] K. Chiba, H. Matsuyuki, Y. Maeda and K. Sugahara, "Role of Sphingosine 1-Phosphate Receptor Type 1 in Lymphocyte Egress from Secondary Lymphoid Tissues and Thymus," Cellular \& Molecular Immunology, Vol. 3, No. 1, 2006, pp. 11-19.

[28] K. Chiba, "Sphingosine 1-Phosphate Receptor Type 1 as a Novel Target for the Therapy of Autoimmune Diseases," Inflammation and Regeneration, Vol. 30, 2010, pp. 160-168.

http://dx.doi.org/10.2492/inflammregen.30.160

[29] L. Kappos, J. Antel, G. Comi, X. Montalban, P. O'Connor, C. H. Polman, T. Haas, A. A. Korn, G. Karlsson and E. W. Radue, "Oral Fingolimod (FTY720) for Relapsing Multiple Sclerosis," New England Journal of Medicine, Vol. 355, No. 11, 2006, pp. 1124-1140. http://dx.doi.org/10.1056/NEJMoa052643

[30] J. A. Cohen, F. Barkhof, G. Comi, H. P. Hartung, B. O. Khatri, X. Montalban, J. Pelletier, R. Capra, P. Gallo, G. Izquierdo, K. Tiel-Wilck, A. de Vera, J. Jin, T. Stites, S. Wu, S. Aradhye and L. Kappos, "Oral Fingolimod or Intramuscular Interferon for Relapsing Multiple Sclerosis," New England Journal of Medicine, Vol. 362, No. 5, 2010, pp. 402-415. http://dx.doi.org/10.1056/NEJMoa0907839

[31] G. Comi, P. O'Connor, X. Montalban, J. Antel, E. W. Radue, G. Karlsson, H. Pohlmann, S. Aradhye and L. Kappos, "Phase II Study of Oral Fingolimod (FTY720) in Multiple Sclerosis: 3-Year Results," Multiple Sclerosis, Vol. 16, No. 2, 2010, pp. 197-207. http://dx.doi.org/10.1177/1352458509357065

[32] L. Kappos, E. W. Radue, P. O’Connor, C. Polman, R. Hohlfeld, P. Calabresi, K. Selmaj, C. Agoropoulou, M. Leyk, L. Zhang-Auberson and P. Burtin, "A PlaceboControlled Trial of Oral Fingolimod in Relapsing Multiple Sclerosis," New England Journal of Medicine, Vol. 362, No. 5, 2010, pp. 387-401. http://dx.doi.org/10.1056/NEJMoa0909494

[33] B. Khatri, F. Barkhof, G. Comi, H. P. Hartung, L. Kappos, X. Montalban, J. Pelletier, T. Stites, S. Wu, F. Holdbrook, L. Zhang-Auberson, G. Francis and J. A. Cohen, "Comparison of Fingolimod with Interferon Beta-1a in Relapsing-Remitting Multiple Sclerosis: A Randomised Exten- sion of the TRANSFORMS Study," The Lancet Neurology, Vol. 10, No. 6, 2011, pp. 520-529.

http://dx.doi.org/10.1016/S1474-4422(11)70099-0

[34] Y. Maeda, H. Matsuyuki, K. Shimano, H. Kataoka, K. Sugahara and K. Chiba, "Migration of CD4 T Cells and Dendritic Cells toward Sphingosine 1-Phosphate (S1P) Is Mediated by Different Receptor Subtypes: S1P Regulates the Functions of Murine Mature Dendritic Cells via S1P Receptor Type 3," Journal of Immunology, Vol. 178, No. 6, 2007, pp. 3437-3446.

[35] S. Thangada, K. M. Khanna, V. A. Blaho, M. L. Oo, D. S. Im, C. Guo, L. Lefrancois and T. Hla, "Cell-Surface Residence of Sphingosine 1-Phosphate Receptor 1 on Lymphocytes Determines Lymphocyte Egress Kinetics," Journal of Experimental Medicine, Vol. 207, No. 7, 2010, pp. 1475-1483. http://dx.doi.org/10.1084/jem.20091343

[36] F. Mullershausen, F. Zecri, C. Cetin, A. Billich, D. Guerini and K. Seuwen, "Persistent Signaling Induced by FTY720-Phosphate Is Mediated by Internalized S1P1 Receptors," Nature Chemical Biology, Vol. 5, No. 6, 2009, pp. 428-434.

http://dx.doi.org/10.1038/nchembio.173

[37] M. Fujino, N. Funeshima, Y. Kitazawa, H. Kimura, H. Amemiya, S. Suzuki and X. K. Li, "Amelioration of Experimental Autoimmune Encephalomyelitis in Lewis Rats by FTY720 Treatment," Journal of Pharmacology and Experimental Therapeutics, Vol. 305, No. 1, 2003, pp. 70-77. http://dx.doi.org/10.1124/jpet.102.045658

[38] M. Webb, C. S. Tham, F. F. Lin, K. Lariosa-Willingham, N. Yu, J. Hale, S. Mandala, J. Chun and T. S. Rao, "Sphingosine 1-Phosphate Receptor Agonists Attenuate Relapsing-Remitting Experimental Autoimmune Encephalitis in SJL mice," Journal of Neuroimmunology, Vol. 153, No. 1-2, 2004, pp. 108-121.

http://dx.doi.org/10.1016/j.jneuroim.2004.04.015

[39] H. Kataoka, K. Sugahara, K. Shimano, K. Teshima, M. Koyama, A. Fukunari and K. Chiba, "FTY720, Sphingosine 1-Phosphate Receptor Modulator, Ameliorates Experimental Autoimmune Encephalomyelitis by Inhibition of T Cell Infiltration," Cellular \& Molecular Immunology, Vol. 2, No. 6, 2005, pp. 439-448.

[40] C. A. Foster, L. M. Howard, A. Schweitzer, E. Persohn, P. C. Hiestand, B. Balatoni, R. Reuschel, C. Beerli, M. Schwartz and A. Billich, "Brain Penetration of the Oral Immunomodulatory Drug FTY720 and Its Phosphorylation in the Central Nervous System during Experimental Autoimmune Encephalomyelitis: Consequences for Mode of Action in Multiple Sclerosis," Journal of Pharmacology and Experimental Therapeutics, Vol. 323, No. 2, 2007, pp. 469-475. http://dx.doi.org/10.1124/jpet.107.127183

[41] B. Balatoni, M. K. Storch, E. M. Swoboda, V. Schonborn, A. Koziel, G. N. Lambrou, P. C. Hiestand, R. Weissert and C. A. Foster, "FTY720 Sustains and Restores Neuronal Function in the DA Rat Model of MOG-Induced Experimental Autoimmune Encephalomyelitis," Brain Research Bulletin, Vol. 74, No. 5, 2007, pp. 307-316. http://dx.doi.org/10.1016/j.brainresbull.2007.06.023

[42] S. R. Schwab, J. P. Pereira, M. Matloubian, Y. Xu, Y. Huang and J. G. Cyster, "Lymphocyte Sequestration 
through S1P Lyase Inhibition and Disruption of S1P Gradients," Science, Vol. 309, No. 5741, 2005, pp. 17351739. http://dx.doi.org/10.1126/science. 1113640

[43] M. G. Sanna, J. Liao, E. Jo, C. Alfonso, M. Y. Ahn, M. S. Peterson, B. Webb, S. Lefebvre, J. Chun, N. Gray and H. Rosen, "Sphingosine 1-Phosphate (S1P) Receptor Subtypes S1P1 and S1P3, Respectively, Regulate Lymphocyte Recirculation and Heart Rate," Journal of Biological Chemistry, Vol. 279, No. 14, 2004, pp. 13839-13848. http://dx.doi.org/10.1074/jbc.M311743200

[44] M. Veldhoen, R. J. Hocking, C. J. Atkins, R. M. Locksley and B. Stockinger, "TGFbeta in the Context of an Inflammatory Cytokine Milieu Supports de Novo Differentiation of IL-17-Producing T Cells," Immunity, Vol. 24, No. 2, 2006, pp. 179-189. http://dx.doi.org/10.1016/j.immuni.2006.01.001

[45] M. O. Li, Y. Y. Wan and R. A. Flavell, "T Cell-Produced Transforming Growth Factor-betal Controls T Cell Tolerance and Regulates Th1- and Th17-Cell Differentiation," Immunity, Vol. 26, No. 5, 2007, pp. 579-591. http://dx.doi.org/10.1016/j.immuni.2007.03.014

[46] Y. Maeda, N. Seki, N. Sato, K. Sugahara and K. Chiba, "Sphingosine 1-Phosphate Receptor Type 1 Regulates Egress of Mature T Cells from Mouse Bone Marrow," International Immunology, Vol. 22, No. 6, 2010, pp. 515525. http://dx.doi.org/10.1093/intimm/dxq036
[47] C. Alfonso, M. G. McHeyzer-Williams and H. Rosen, "CD69 Down-Modulation and Inhibition of Thymic Egress by Short- and Long-Term Selective Chemical Agonism of Sphingosine 1-Phosphate Receptors," European Journal of Immunology, Vol. 36, No. 1, 2006, pp. 149159. http://dx.doi.org/10.1002/eji.200535127

[48] M. A. Kroenke, T. J. Carlson, A. V. Andjelkovic and B. M. Segal, "IL-12- and IL-23-Modulated T Cells Induce Distinct Types of EAE Based on Histology, CNS Chemokine Profile, and Response to Cytokine Inhibition," Journal of Experimental Medicine, Vol. 205, No. 7, 2008, pp. 1535-1541. http://dx.doi.org/10.1084/jem.20080159

[49] I. M. Stromnes, L. M. Cerretti, D. Liggitt, R. A. Harris and J. M. Goverman, "Differential Regulation of Central Nervous System Autoimmunity by $\mathrm{T}(\mathrm{H}) 1$ and $\mathrm{T}(\mathrm{H}) 17$ Cells," Nature Medicine, Vol. 14, No. 3, 2008, pp. 337342. http://dx.doi.org/10.1038/nm1715

[50] L. Steinman, "Mixed Results with Modulation of TH-17 Cells in Human Autoimmune Diseases," Nature Immunology, Vol. 11, No. 1, 2010, pp. 41-44. http://dx.doi.org/10.1038/ni.1803

[51] J. J. Liao, M. C. Huang and E. J. Goetzl, "Cutting Edge: Alternative Signaling of Th17 Cell Development by Sphingosine 1-Phosphate," Journal of Immunology, Vol. 178, No. 9, 2007, pp. 5425-5428. 